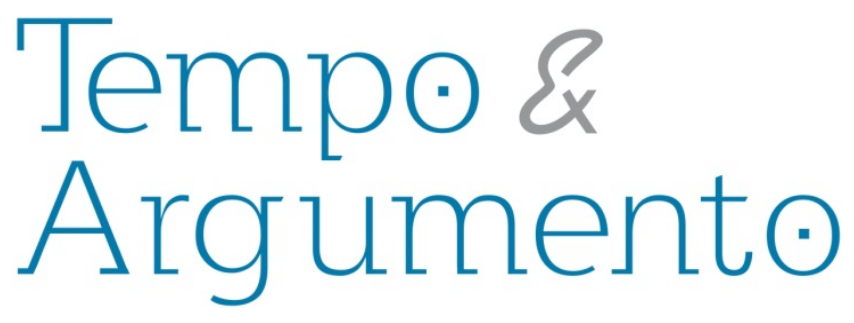

\title{
Construcciones y experiencias de la infancia en un contexto migratorio: el caso de los alemanes en México (1900-1933)
}

\begin{abstract}
Resumen
Por mucho tiempo, buena parte del trabajo académico y de las narrativas populares transmitieron la imagen de que la experiencia de ser un niño de orígenes alemanes creciendo en México era equivalente a una infancia privilegiada, pero, al mismo tiempo, aislada de la sociedad receptora. Esta contribución considera esas construcciones y experiencias de la niñez, al mismo tiempo que las compara con las de otros 114 casos, provenientes de 72 familias, que fueron compilados para este objetivo en una base de datos. En ese proceso, se da visibilidad a otras vivencias de la infancia que hasta ahora no han sido discutidas. En este análisis etno-histórico, se reflexiona sobre los diversos contextos socioeconómicos que generan variadas formas de experimentar la infancia. Se proporciona información sobre las maneras en que aquellos menores se relacionaron con la sociedad de acogida, sobre las relaciones transnacionales que cultivaron o no, y sobre lo que podría haber motivado a sus padres a continuar, o descartar, ciertas prácticas culturales. Los resultados indican que, en lo que respecta a la mayoría de los descendientes de alemanes en México durante el tiempo estudiado, no es posible hablar de una separación casi total de la sociedad receptora; en vez de eso, diversas estrategias de aculturación fueron identificadas. Se demuestra, al mismo tiempo, que la ascendencia extranjera no necesariamente va mano en mano con una infancia transnacional, sino que depende de varios factores que se intenta identificar.
\end{abstract}

Palabras clave: Migración; Infancia; Alemanes; Aculturación; Imaginarios sociales.

\author{
Alma Durán-Merk \\ Doctora en Antropología Histórica por \\ la Universidad de Augsburgo, donde \\ colabora como catedrática e \\ investigadora. \\ Alemania \\ alma.duran@phil.uni-augsburg.de
}

\section{Para citar este artículo:}

DURÁN-MERK, Alma. Construcciones y experiencias de la infancia en un contexto migratorio: el caso de los alemanes en México (1900-1933). Revista Tempo e Argumento, Florianópolis, v. 7, n. 14, p. 85 - 115, jan./abr. 2015. 
Constructions and experiences of childhood in a migratory context: the case of the Germans in México (1900-1933)

\begin{abstract}
For a long time, scholarly work and popular narratives conveyed the image that the experience of being a child of German origins growing up in México was equivalent to a privileged childhood; according to those accounts this process was experienced at the price of isolation from the host society. This contribution looks at some of those constructions of childhood and their concomitant experiences. Simultaneously, these are contrasted against those arising from other 114 cases, from 72 families, which were gathered in a database for the purpose of being analyzed. This comparative process provides visibility to other children's experiences that have not been yet part of the academic discourse. In this ethnohistorical analysis, we think through the various socioeconomic contexts that generated different childhood experiences. Information on the ways in which those children related to the host society is provided. The issues of whether transnational relationships were cultivated or not is approached, as well as the factor that could have motivated the parents of those minors to keep, or reject, certain cultural practices. The results indicate that most Germans descendants in México during the period studied did not find themselves in an almost total separation from the host society; instead, various acculturation strategies were identified. It is shown, at the same time, that foreign ancestry not necessarily goes hand in hand with a transnational childhood, but that it depends on several factors we aim to identify.
\end{abstract}

Keywords: Migration; Childhood; Germans; Acculturation; Social constructions.

\section{Construções e experiências da infância em um contexto migratório: o caso dos alemães no México (1900- 1933)}

\section{Resumo}

Por muito tempo, boa parte do trabalho acadêmico e das narrativas populares transmitiu a imagem de que a experiência de ser uma criança de origens alemãs crescendo no México era equivalente a uma infância privilegiada, mas, ao mesmo tempo, isolada da sociedade receptora. Esta contribuição considera essas construções e experiências da infância, ao mesmo tempo que as compara com as de outros 114 casos, provenientes de 72 famílias, que foram compilados para este objetivo em uma base de dados. Neste processo, dá-se visibilidade a outras vivências da infância que até agora não foram discutidas. Nesta análise etno-histórica, reflete-se sobre os diversos contextos socioeconômicos que geram variadas formas de experimentar a infância. Oferecem-se informações sobre as maneiras pelas quais aqueles menores se relacionaram com a sociedade receptora, sobre as relações transnacionais que cultivaram ou não, e sobre o que poderia ter motivado seus pais a continuar, ou descartar, algumas práticas culturais. Os resultados indicam que, no que diz respeito à maioria dos descendentes de alemães no México durante o tempo estudado, não é possível falar de uma separação quase total da sociedade receptora; em vez disso, diversas estratégias de aculturamento foram identificadas. Demonstra-se, ao mesmo tempo, que a ascendência estrangeira não está necessariamente de mãos dadas com uma infância transnacional, mas que depende de vários fatores que se busca identificar.

Palavras-chave: Migração; Infância; Alemães; Aculturamento; Imaginários sociais. 


\section{Introducción}

En el imaginario popular aún prevalece la idea de que las experiencias de la infancia de descendientes de alemanes en México equivalen a una niñez privilegiada y, al mismo tiempo, desconectada de la sociedad receptora. Este tipo de prácticas son narradas usualmente por miembros de familias que pertenecieron a las élites comerciales de la capital mexicana hacia el paso al siglo XX. Así, en un excelente análisis familiar, el historiador Jürgen Buchenau (2004, pp. 104-106) describe niños a quienes sus padres deseaban mantener aislados de las que se imaginaban como "perniciosas" influencias de la sociedad mexicana. De acuerdo con un testimonio dado por Gabriele Boker de Pocorny, hija de alemanes nacida en la Ciudad de México en 1905, ese estilo de vida que prohibía relaciones con mexicanos, que apocaba el uso del idioma español, y que desalentaba el interés por la cultural del país receptor, fue experimentado como el "crecer bajo [una] campana de cristal" (BUCHENAU, 2004, p. 104).

Hay, sin embargo, otros tipos de recuerdos que hasta ahora no han sido estudiados y que contrastan grandemente con las prácticas anteriormente expuestas, dando más bien testimonio de infancias muy variadas. Algunas de esas narrativas y experiencias muestran procesos de transculturación, entendiendo bajo este término los fenómenos sociales de transmutación de culturas, y cuyos resultados son únicos, creativos y enriquecedores (ORTIZ, 1973, p. 129; WELSCH, 2009). Esos ejemplos retratan personas que crecieron en círculos de amistades que incluían alemanes, habitantes originarios de la localidad y personas de otras nacionalidades (ROJAS MARíN, 2012; DURÁNMERK, 2015). En otras instancias, las reminiscencias enfatizan una infancia vivida intensamente en una región mexicana específica, lo cual conllevaba a una fuerte identificación con esa geografía y cultura. Otras veces lo que las personas narran restrospectivamente es que aún y cuando tuvieron raíces alemanas llevaron infancias de niños campesinos en áreas rurales -ya sea por haber quedado huérfanos, por haber sido abandonados, o simplemente porque sus padres pertenecieron a los sectores populares desde el momento en que migraron.

Desde la perspectiva de la antropología histórica, este análisis examina los relatos que proporcionan información sobre las formas en que diversas personas recuerdan 
haber experimentado su infancia, reconstruyendo también algunas vivencias a través de fuentes documentales. Cabe aclarar que los términos “niño”, “pequeño”, “menor”, “chico" y "chiquillo" -así como sus formas plurales- son aquí utilizados para referirse tanto a varones como mujeres menores de 15 años; aquellos y aquellas entre los 16 y los 18 años son considerados como “jóvenes”.

Este estudio se concentra, entonces, en las huellas documentales sobre las experiencias, y/o las narrativas sobre las mismas, emitidas por personas de ascendencia alemana en México quienes vivieron cuando menos parte de su niñez en este país durante las primeras tres décadas del siglo XX. Esta etapa ha sido elegida por varias razones: primero, el acceso a datos primarios y secundarios sobre casos específicos. Segundo: durante ese período además de los alemanes que ya venían residiendo en el país por varias décadas (MENTZ et. al., 1988), algunos nuevos inmigrantes de ese origen continuaron llegando al país: éstos reaccionaban a cambios históricos y de las políticas migratorias, y/o oportunidades ocupacionales vigentes en ambos países. El tercer factor de influencia fue la existencia de literatura secundaria sobre la infancia en México a la cual se puede recurrir para ubicar apropiadamente los sucesos.

El sitio desde el que se observa el fenómeno es la cultura de las clases medias de la sociedad receptora, preguntando en qué medida niños de diversas culturas o naciones compartieron espacios, ideas y prácticas cotidianas. Mi atención se centra en dos fenómenos que forman parte de la experiencia migratoria. Primero, los procesos de aculturación, o sea, intento identificar tanto en las fuentes documentales como en las narraciones aquellos indicadores que proporcionan información sobre los modos de aculturación que aquellos chicos experimentaron. De acuerdo con John W. Berry (2003) al encontrarse con una nueva cultura los inmigrantes pueden recurrir a cuatro modalidades de aculturación básicas que de ninguna son estáticas ni lineales: segregación, integración, marginalización, o asimilación. Dos preguntas ayudan a dilucidar qué tipo de estrategias fueron seguidas: ¿En qué medida se enfatizaba el mantener la propia herencia cultural y la identidad étnica? y ¿Qué tipo y calidad de relaciones se mantenían con miembros de la sociedad de acogida? Hay que resaltar que, desde la perspectiva de la antropología, las consecuencias de una migración no se miden únicamente considerando el éxito 
económico: igualmente importantes son las dimensiones culturales, sociales, y de identificación. Además, hay que considerar no sólo al individuo, sino también a la familia y a la comunidad étnica. El segundo aspecto a inspeccionar aquí es la transnacionalización, entendida como los procesos por medio de los cuales los inmigrantes construyen campos sociales que conectan de manera cotidiana sus países de origen y aquellos en los que se han asentado (GLICK SCHILLER et. al., 1992).

Este trabajo se basa en el análisis de datos correspondientes a 114 casos, derivados de 72 familias, los cuales son parte de la Database German-Mexicans, 1865-1930 (DURÁNMERK, 2014). La información que compone dicha base referencial proviene mayoritariamente de fuentes primarias obtenidas a través de métodos etno-históricos, especialmente entrevistas, y es complementada por literatura secundaria -en este último caso, se dan aquí las referencias pertinentes.

El presente reporte está dividido en cuatro partes: la primera sitúa la infancia en el contexto migratorio, la segunda analiza el imaginario dominante que corresponde al contexto histórico analizado, en tanto la tercera propone una clasificación de las infancias identificadas como resultado del análisis aquí realizado. A modo de cierre son presentadas las variables que parecen haber afectado aquellos encuentros.

\section{Migración e infancia}

Las migraciones son procesos fluidos y se pueden considerar tan normales como la vida sedentaria (CASTLES y MILLER, 2003). Una reubicación, por una parte, envuelve tránsitos, inseguridades, acomodamientos, retornos, pérdidas y a veces re-migraciones. Por la otra, esta forma de movilidad abre las puertas para la recreación de aspectos conocidos, la importación de ideas, la adquisición de nuevas habilidades, la revalorización de prácticas culturales, el desarrollo, etc. (LUCASSEN y LUCASSEN, 2005; BRETTELL, 2008). Se considera a alguien como migrante cuando ha residido cuando menos por un año completo en un país diferente al de su origen (UNITED NATIONS, 2000).

En la migración, los recién llegados experimentan simultáneamente lo regional, lo nacional y lo transnacional. Toda reubicación -incluida la de niños y jóvenes- está situada 
MAHLER y PESSAR, 2006). Habría que considerar, además, los procesos de de-clasificación que pueden conllevan las reubicaciones transatlánticas en círculos culturales disímiles: esto significa que algunas personas se ven forzadas a aceptar trabajos en el país de acogida que están mal remunerados, no traen consigo prestigio social, y/o están por debajo de su capacidad.

Es común que en una migración se dé un encuentro intercultural cuyos resultados pueden ser, entre otros, el compartir y disfrutar de experiencias, o el interactuar, amalgamar o influenciar al otro, pero también el chocar, el enfrentarse con otros, el aislarse, o el ser empujado a la marginalidad. Estas vivencias llevan normalmente a una conceptualización de “El Otro" y con ello a una redefinición de uno mismo (KRIST y WolfsberGer, 2009). Esto explica el que muchos niños no estén conscientes de pertenecer a una "etnia" sino hasta que experimentan una migración. Este marcador de identidad -ya sea adscrito o voluntariamente adoptado- afectará a las siguientes generaciones. Especial atención debe prestarse a la llamada generación 1.5, la cual es conformada, siguiendo la definición propuesta por Rubén G. Rumbaudt (1997), por aquellos y aquellas que contaban con menos de 15 años de edad al llegar al país receptor. Asi pues, la socialización de esos pequeños se efectuó en cuando menos dos culturas diferentes. En este subgrupo es interesante tratar de identificar qué tipo de preferencias y afiliaciones prevalecieron a los niveles de prácticas, discursos e imaginarios, y el porqué de su prominencia, mezcla, o abandono.

\section{Alemanes en México y los imaginarios sobre la infancia}

Si bien hasta ahora se han postulado múltiples tipos de infancias y sus representaciones para distintas épocas, regiones y subgrupos sociales (DEL CASTILLO Troncoso, 2006; Salazar Anaya, 2006; Salazar Anaya y SÁnchez Calleja, 2008; Blum, 2009; GRANJA CASTRO, 2013; SOSENSKI y AlBARRÁn, 2012), hay pocas propuestas sobre las vidas de 
En lo que respecta a los hijos de migrantes en México durante el período aquí estudiado es posible afirmar, en general, que aquellos niños que pertenecían a grupos culturales subalternos eran vistos como mano de obra barata. Por ejemplo, al analizar las descripciones del clima de recibimiento que se dio a los inmigrantes coreanos en Yucatán en 1905, entre los que había un buen número de niños, se insinúa que ellos también son parte de los trabajadores que llegaron "para los servicios agrícolas" en diversas haciendas del Mayab (Corona Baeza, 2005; Romero CASTILLA, 1997). En el otro extremo, a los descendientes de conglomerados con más prestigio social, como los centro-europeos y los norteamericanos, se les imaginaba inicialmente como dependientes acomodados (PIERCE, 1996; DURÁN-MERK, 2015).

Para comprender esta construcción es necesario considerar que desde la Independencia de México buena parte de las élites locales asignó de entrada a los alemanes una respetabilidad y estatus social superior en el país, eligiendo ignorar las diferencias socio-culturales de origen entre los emigrados. Sólo para dar un ejemplo: de acuerdo con el historiador George Dieter Berninger (1974), los inmigrantes de países de habla alemana eran idealizados como muy trabajadores, poco pretenciosos, apolíticos y anglófobos, lo cual no necesariamente correspondía con la realidad. Estos estereotipos fueron el resultado de lastres coloniales y de la ideología racista aún imperante en algunos grupos dominantes locales. Especialmente después de la creación del Estado Alemán en 1871, esta idealización de los migrantes alemanes en México como una migración de elite se vio reforzada por las actividades comerciales exitosas que ciertos inmigrantes de ese origen realizaron durante el Porfiriato, o sea entre 1876 y 1910. Durante esa época, algunos de ellos aprovecharon la política imperialista del Segundo Reich y los privilegios que la dictadura porfirista les dio en México, al mismo tiempo que tornaron en ventaja a su favor algunas debilidades estructurales del país que los acogió, utilizando diversas estrategias para incrementar su capital (GONZÁLEZ NAVARRO, 1993 y 1994: Mentz et. al., 1982 y 1988; BuchenAu, 2004). 
Un aspecto que hay que resaltar es que, contrariamente a lo que se asumió por muchas décadas, la migración alemana a México no fue exclusivamente una migración de elite, sino que fue heterogénea. Si bien el trabajo de investigación sobre este grupo étnico en México se centró por varias décadas en el análisis de élites, desde principios del siglo XXI hay más interés en dar visibilidad a las historias migratorias de gente común y corriente. La mayor parte de los estudios tradicionales asumían que todos los inmigrantes eran personas acomodadas desde su llegada al país, o bien creían que los ejemplos de las clases acomodadas capitalinas que habían estudiado representaban la totalidad de las experiencias. En contraste, trabajos más recientes se esfuerzan por entender los mecanismos por medio de los cuales algunos inmigrantes de modestos medios lograron acumular un cierto capital, considerando al mismo tiempo las características de las comunidades regionales específicas (ORTOlL, 2005; PRECIAdo ZAMORA, 2007; RoJAs MARín, 2012; MÉNDEZ REYES, 2014; DURÁN-MERK, 2014 Y 2015). Gracias a estas nuevas investigaciones, sabemos que para la época que nos ocupa se encontraban en México no solo vástagos de acaudalados negociantes y de profesionistas, sino también descendientes de técnicos, de trabajadores, de artesanos, de campesinos, de empleados, y de comerciantes medianos o menores. Los alemanes que llegaron a México en la primera mitad del siglo XX pertenecerían a variados grupos socioeconómicos y políticos: si bien antes de 1910 un buen número de personas de los sectores altos y medios emigraron, después de 1919 eran más que nada personas que trataban de escapar la pobreza de la Alemania de la posguerra y conservadores que no aceptaban la República de Weimar. A partir de 1933, el principal motivo para emigrar sería el escapar de la Alemania nazi. Si bien es cierto que algunos de estos inmigrantes vivieron solos, algunos de ellos trajeron a sus familias y muchos más formaron éstas en las localidades donde radicaron -mayoritariamente con personas mexicanas.

En relación a cómo se concebía la niñez, hay diferencias que dependen a grosso modo de los sectores socio-económicos a los que se pertenecía. Las clases acomodadas fácilmente se identificaban con las entonces bien arraigadas ideas románticas sobre la infancia. En Europa, y específicamente en el caso de Alemania, esta modificación de imaginarios se empezó a gestar entre las clases superior en el siglo XVIII, con la 
separación entre lo que se consideraba apropiado para los niños y lo que era sólo para adultos (MESCHENDÖRFER, 1991). Resumiendo las características de esa visión, se puede decir que los niños eran considerados como seres puros e indefensos a los que había que proteger y educar; se daba importancia a la instrucción temprana, a la educación y a la salvación espiritual. La infancia era idealizada como la mejor etapa de la vida, sin tomar en cuenta que había clases sociales subalternas en las que este imaginario no aplicaba (CUNNINGHAM, 2005). Al reflexionar sobre esa concepción, es posible darse cuenta de que esa visión no era atributo exclusivo de los europeos ni de los alemanes pudientes, sino más bien una idea compartida con los estratos equivalentes de la sociedad mexicana.

En contraste, desde el siglo XVII entre las clases trabajadoras tanto rurales como urbanas de los Estados Alemanes se imponía otra visión de la infancia, la cual no se limitaba a un nivel discursivo sino abarcaba prácticas e imaginarios. La tendencia común era a considerar a los niños como elementos que compartían por igual el destino y la vida de la familia y que debían colaborar para el sostenimiento de la misma (MESCHENDÖRFER, 1991; JACOBEIT y JACOBEIT, 1987). Para los niños mexicanos de las clases trabajadoras, y para aquellos que habían quedado desamparados, la situación era bastante parecida hasta bien entrado el siglo XX. Se puede hablar de una cierta convergencia entre las formas de vida cotidiana de aquellos extranjeros de los sectores menos favorecidos y las de los mexicanos de los sectores subalternos.

Por lo tanto, es apropiado hablar de una diferenciación de imaginarios -y quizá de prácticas- ligado a una estratificación social y a condiciones macro estructurales, más que específicamente unido a una procedencia nacional o a la identidad cultural un conglomerado.

Además, en el caso alemán en concreto hay que tomar en cuenta dos puntos en el tiempo cuando, argumentando distinciones biológico-culturales, algunos miembros de ese grupo promovieron actitudes altamente segregacionistas que impactaron las experiencias de muchos infantes: durante lo que podríamos llamar la época “dorada” para esos individuos, o sea durante el Porfiriato (1876-1910) y bajo el Tercer Reich (19331945). Personas de esa comunidad distinguían marcadamente entre niños alemanes “puros", o sea hijos de alemanes, y los que eran producto de relaciones interculturales. 
Cual si se tratase de una ley natural, estos últimos eran estigmatizados bajo el argumento de que "los hijos de padres mezclados siempre serían malas personas"."

\section{Infancias de niños de ascendencia alemana en México}

Analizando en qué medida los niños de ascendencia alemana se relacionaron de forma significativa con sus iguales mexicanos, y considerando en qué medida compartieron experiencias cotidianas con éstos, es posible identificar ocho subgrupos durante el período estudiado: infancias de segregación, transnacionales, biculturales, multiculturales, en tres culturas, regionales con referencias a Alemania, de integración a las clases trabajadoras locales, y las de hijos no reconocidos.

\section{Infancias de segregación}

Durante buena parte del tiempo de que hablamos el discurso predominante entre este subgrupo era que "en contacto con otras naciones, puede el alemán perder sus mejores cualidades a menos de que de forma consciente, y consecuente, mantenga y cultive su particularidad". 2

Ejemplificado por el caso con el que inició este texto, los pequeños que crecieron en hogares en que se cultivaba esa ideología fueron normalmente aislados de la cultura mexicana por sus padres. Experiencias de este tipo se encontraron entre las clases altas de la Ciudad de México hasta las vísperas de la Segunda Guerra Mundial. Con muy pocos contactos con miembros de la sociedad de acogida y tomando una posición de superioridad ante ellos, los círculos en que estos menores se movían estaban compuestos mayoritariamente de compatriotas de su mismo estrato. Comparando la información con la literatura que ha estudiado en detalle las formas de vivir de las élites mexicanas (ADLER DE LOMNITZ y PÉREZ-LIZAUR, 1987), es posible identificar algunos paralelos entre las acciones

\footnotetext{
${ }^{1}$ Carta de Heinrich Ude a su madre, Torreón, Coahuila, 23.11.1938, texto completo en Ekkehard LAURITZEN, "Briefe aus Mexiko. Heinrich Ude: Aus Lübeck nach Mexiko", no. 21.03.2010 (2006), http://www.lauritzen-hamburg.de/ude_mexico.html, (consultado 20.05.2011).

${ }^{2}$ Bundesarchiv Berlin-Lichterfelde, R/901/39205, E. Schöndube al Auswärtiges Amt, Berlín, México, 30.03.1900.
} 
Siendo mayoritariamente producto de matrimonios germanos y habiendo sido educados en el Colegio Alemán, los niños que allí estudiaron poco o casi nada aprendían sobre el país en que nacieron; en esa institución era donde continuaban con las prácticas y rituales propios de la infancia y la juventud en Alemania. Hasta el final del Porfiriato, eran frecuentes los casos en que estos niños mantenían el alemán como primer idioma, y apenas hablaban un español rudimentario (BUCHENAU, 2004). Otros aspectos comúnmente enfatizados por la educación que ofrecía el Colegio Alemán eran la fuerte disciplina prusiana y la ética protestante (MENTZ DE BOEGE, 1988). Hay, sin embargo, que estar conscientes de que un cierto número de mexicanos atendía también esa escuela, lo cual habría posibilitado ciertas interacciones que hasta hoy permanecen inexploradas en el ámbito académico. Hay que distinguir, así mismo, que el Colegio Alemán en la Ciudad de México pasó por diversas etapas en cuanto a su auto-segregación cultural entre 1894 y 1842 (MENTZ DE BOEGE, 1988) y también que reconocer que la vida cotidiana en las escuelas alemanas en otras ciudades mexicanas más pequeñas no ha sido apropiadamente estudiada. Esto significa que habría que trabajar en estudios de caso que miren con detalle las condiciones específicas de situaciones particulares.

Para aproximarnos al imaginario en que estos pequeños crecieron, hay que tomar en cuenta también que la noción que se transmitía a estos niños de Alemania después de la Primera Guerra Mundial se basaba en una concepción irreal y empolvada que añoraba las perdidas glorias del Imperio. Un buen número de los descendientes de familias de comerciantes de nivel alto vivió y estudió por algunos en Alemania. Esto, por cierto, no fue un fenómeno exclusivo de México, sino que sucedió también en otras latitudes (HoffmAnN, 2009). Ciertos descendientes regresaron a la antigua patria, creyendo que sería para siempre. No obstante, especialmente después de 1918, existieron múltiples casos de re-migración a México. Estas familias retornaron, como en el caso de los Boehm Rowe, porque no veían ningún futuro en la Alemania derrotada (DURÁN-MERK, 2014 y 2015) y porque consideraban que tenían mejores posibilidades de rehacer sus fortunas en este 
Es vital recalcar que esta clase social ha dejado múltiples huellas que indican una doble moralidad en cuanto a la visión de la infancia: resguardaban a los propios, pero usaban a aquellos de los sectores subalternos. Por ejemplo, algunos de los mismos alemanes que, como hemos visto arriba, sobreprotegían a sus descendientes (BUCHENAU, 2004) no tuvieron ningún empacho en explotar niños y adolescentes mexicanos como mano de obra barata en sus negocios (SOSENSKI, 2010, p. 104f).

¿Se puede hablar de que la experiencia de la mayoría de los descendientes de alemanes acaudalados en México fue cultural y socialmente transnacional? Durante el período que nos ocupa, difícilmente, ya que un chovinismo excesivo llevaba a buena parte de este subgrupo a desdeñar, o hasta despreciar, otras tradiciones. Sin embargo, ya como adultos, algunos supieron capitalizar su conocimiento de México, aprovecharon la buena educación académica que obtuvieron y se beneficiaron de los múltiples contactos internacionales con que contaban. Varios de ellos hicieron negocios económicamente exitosos.

\section{Infancias transnacionales}

Estamos hablando, de nuevo, sobre hijos de padres pertenecientes a los estratos económicos dominantes. No sólo en la Ciudad de México, sino también en otras capitales estatales de la República, se encontraron algunas familiar de elite con contactos internacionales.

En aquellas locaciones donde existía un Colegio Alemán, los descendientes de germano-hablantes eran enviados ahí, pero esto no significaba necesariamente un aislamiento total. Si la familia vivía en localidades más pequeñas, maestros privados eran traídos de Alemania (Rojas MARín, 2012; Durán-Merk, 2015). Algunos de aquellos pequeños establecían relaciones importantes con mexicanos que estudiaban también en el Colegio Alemán, y/o con otros niños con quienes compartían actividades en áreas habitaciones exclusivas, en clubes deportivos, o en reuniones sociales. 
Con frecuencia, uno de sus padres era mexicano, o bien descendiente de extranjeros ya nacidos y educados en México. A esos pequeños se les permitía hablar español en el contexto familiar y social; escribían y leían también en ambos idiomas. Normalmente sus padres les daban nombres que existían en ambos lenguajes, como María, Olga, Juan (Johannes), Federico (Frederick) o Hugo, por ejemplo. En cuanto a prácticas religiosas, algunos pocos continuaron su afiliación al Protestantismo. La mayoría, sin embargo, era registrada desde su nacimiento como Católica, aunque algunos participaban en ritos familiares multigeneracionales de ambas religiones. Otros cuantos se consideraban ateos.

Dada la relevancia simbólica del bautismo y de la confirmación entre todas las clases sociales en México (MinTz y Wolf, 1950; BerGhe y BerGhe, 1966; AdLeR De LomnitZ, 1985), el presente análisis ha prestado especial atención a este tipo de rituales, considerando en detalle quienes fungían como padrinos. Los chicos criados en ambientes transnacionales fueron apadrinados en su mayoría, pero no exclusivamente, por personas de la comunidad étnica; el resto era elegido entre miembros de las elites locales.

Las infancias de estos menores correspondían -en cuanto a prácticas e imaginarios culturales- a aquellas de los estratos locales acomodados, aunque conservando ciertas costumbres alemanas, como la de celebrar la Navidad. Al mismo tiempo, estos chiquillos cultivaban conexiones familiares en Alemania, país que solían visitar cuando menos cada año; siguiendo a sus padres, algunos de ellos vivían en cada país por temporadas, sintiéndose a gusto en ambos contextos. Ya que asociaban sus estancias en Alemania con fuerte disciplina y muchas demandas, apreciaban regresar a México donde se sentían más libres. Ese ir y venir entre contrastes los ayudaba, según dicen sus descendientes, a “acostumbrarse rápido a todo” y los llevaba a ser personas más flexibles y adaptables.

Ya como adultos, al formar una familia, bien podrían elegir una persona nacida en México como cónyuge, pero de su propio estatus social. Se trataba de una endogamia de clase, más que étnica. La identidad nacional preferente era normalmente alemana, pero las personas no necesariamente soñaban con un retorno a ese país, especialmente después de 1919 (DURÁN-MERK, 2015). 
De acuerdo con la definición proporcionada al principio de este ensayo, este es el subgrupo del que se puede decir que tuvo una infancia transnacional. Tanto las actividades cotidianas como los discursos y las redes familiares y sociales envolvían de manera cotidiana las dos sociedades en que crecieron.

\section{Infancias biculturales}

Infancias donde coincidían prácticas, idearios, y discursos populares de ambas culturas fueron encontrados en mayor abundancia entre descendientes de matrimonios mixtos y entre familias urbanas de provincia pertenecientes a las clases medias superiores, sobre todo entre profesionistas liberales y comerciantes medianos. Si bien en el siglo XIX las esposas mexicanas de alemanes se apegaban a las prácticas culturales de sus maridos (MENTZ, 1982, p. 352), todo indica que la situación cambió hacia los inicios del siglo XX en buena parte de las geografías.

Los datos analizados muestran claramente que en la época estudiada el hecho de que la madre fuera mexicana no significó automáticamente que los hijos fueron formados con un mayor apego a la tradición alemana, en detrimento de la mexicana. De hecho, desde principios del siglo XX, el Cónsul de Alemania en México, Graf von Bülow, se quejaban de que en la provincia "los padres están siempre ocupados en sus negocios, y los niños escuchan todo el día español de sus madres, ya que la mayoría son mexicanas, y de los sirvientes de la casa". 3 Como consecuencia de tan "desafortunada" situación, escribió el diplomático, la “mexicanización” se daba desde la segunda generación. A pesar de los deseos del Reich para evitar esa integración, las narrativas recopiladas y los testimonios documentales dan testimonio de que un buen número de chiquillos se afianzaron mejor en la cultura de México a través de la línea maternal y de los círculos sociales en que crecieron, en especial si la madre era de una familia local de elite y si el padre alemán provenía de las clases medias (DURÁN-MERK, 2015; RoJAS MARíN, 2012).

\footnotetext{
${ }^{3}$ Bundesarchiv Berlin-Lichterfelde, R/902/39207, Kaiserliche Gesandschaft Mexiko a Reichskanzler, Grafen von Bülow, México, 28.03.1905.
} 
A pesar de que hay varias similitudes con el subgrupo anteriormente mencionado, la gran diferencia es el contacto más limitado con Alemania: Ios niños de estas familias no contaban con parientes en el viejo continente que los recibieran y educaran, y sólo una minoría tenía el dinero necesario para visitar ese país de vez en cuando. Esto significa que aunque teniendo contactos, éstos no tenía las cualidades ni la intensidad necesarias para crear formas de vida transnacionales. De hecho, la gran mayoría de estos menores fue a Alemania sólo por temporadas relativamente cortas, y ya más bien como adolescentes o como adultos jóvenes.

Estos niños llevaban nombres en español que, con gran frecuencia, hacían referencia a la tradición religiosa mexicana, como María de los Remedios o Francisco José. El contar con amistades locales, la asistencia a escuelas católicas privadas donde se hablaba exclusivamente el castellano, y las extensas e intensivas redes de parentesco local parecen haber influenciado una preferencia por las prácticas culturales de la localidad. El idioma alemán, sin embargo, no quedaba totalmente relegado, sino que era aprendido a un nivel básico gracias a maestros particulares o bien en escuelas de idiomas locales. Es en este grupo donde más claramente se observan diferencias de género: los varones eran cuando menos parcialmente preparados en Alemania para una educación comercial y tenían más contacto con el idioma y los imaginarios de esa cultura. Hasta el inicio de la Primera Guerra Mundial eventualmente algunos niños pertenecientes a los grupos más pudientes eran enviados a Alemania a estudiar por un par de años. Comúnmente, esa experiencia en el exterior les revelaba que no eran tan "alemanes" como creían. En contraste, el número de niñas a las que se brindó la oportunidad de obtener una educación en Alemania fue muy bajo. Apegadas a las madres mexicanas, se les mantenía más asentadas en las tradiciones locales.

Aquellos con una fisonomía "europea” enfatizaban ésta como marcador de identidad en sus discursos; para aquellos con rasgos más mezclados el factor económico imprimía la diferencia entre ser aceptado como "alemán” o no. En materia identificativa, se encuentran marcadas diferencias: mientras que los menos aún conservaban la nacionalidad de sus padres, los más se decían alemanes aunque en realidad sólo tenían pasaporte mexicano; otros se autonombraban mexicanos de descendencia alemana. El 
cambio radical a favor de una identificación con el estado-nación mexicano se dio en 1942, con la entrada de México en la Segunda Guerra Mundial. La mayoría de aquellos niños, al crecer, contrajo matrimonio con ciudadanos mexicanos.

\section{Infancias multiculturales}

El fenómeno que ahora llamamos nomadismo económico se detecta ya a principios del siglo XX. En el caso de este subgrupo, estamos hablando de miembros de la generación 1,5 quienes vivieron en varios países ya que la familia, siguiendo oportunidades de trabajo, cambiaba con cierta frecuencia de residencia. Cabe subrayar que la información analizada indica que no siempre se trató de miembros de las élites.

Con a lo menos un padre de origen alemán, las infancias de los pequeños que aquí se considera se desarrollaron en múltiples países. Esto significa que fueron socializados en varios marcos culturales. Sólo por dar dos ejemplos: los descendientes de la pareja alemana formada por Emma Milke y Otto Milke crecieron en los Estados Unidos, en Haití, en Jamaica y en diversas locaciones en México. En otro caso, miembros de la familia Meinhardt Krosker vivieron parte de sus vidas en Alemania, en Francia, en Argelia, en Venezuela y, finalmente, en México (DURÁN-MERK, 2015).

Este es el conglomerado donde se encuentra la mayor parte de configuraciones identitarias múltiples; éstas llevan normalmente a una afiliación cultural y nacional situacional, o sea, altamente variable dependiendo de las circunstancias. Por eso no debe sorprendernos que esos individuos a veces hablan de ellos mismos como alemanes, otras como norteamericanos o, en otras más, como franceses, por ejemplo. Depende normalmente del contexto histórico-social específico que tratan de narrar. Usualmente, indican que en su infancia utilizaron varios idiomas para expresarse, aunque con grandes diferencias en cuanto a la capacidad de escribirlos y de leerlos; es también notorio que aprendieron sólo las bases para hablar alemán, con una clara preferencia a expresarse oralmente, leer y escribir ya sea en inglés o en español.

Mientras que algunos regresaron a Alemania o a Europa después de haber vivido algunos años en varios países del continente americano, una buena parte se quedó en 
México y vivió en provincia. Estos menores se incorporaron a la sociedad local a través de actividades, de rituales, de la utilización de espacios, y del compartir múltiples experiencias cotidianas con niños de otras culturas provenientes de las clases medias ascendentes o de los estratos acomodados. Es frecuente encontrar en los testimonios frases que indican que si bien no eran ricos, eran socialmente aceptados por su ascendencia europea. Resulta interesante que en especial las preferencias y prácticas alimenticias de estos niños exhibían influencias de las múltiples culturas con las que habían estado en contacto.

\section{Infancias en tres culturas}

Sería un error interpretar estos niños como Third-Culture-Kids, concepto creado en los años 60 para estudiar a los hijos de familias acomodadas viviendo en el extranjero (USEEM y DownIE, 1976, pp. 103-105). En el México de principios del siglo XX, la gran mayoría de los casos estudiados se situaba entre las clases medias. En esta clasificación se incluyen miembros de las generaciones 1.5 y 2, provenientes de un padre alemán y otro de un círculo cultural distinto, que nacieron y/o crecieron en México. Por sólo mencionar un caso: los niños de la familia Barone Shapiro -Alberto Benedict, Emma, Francisco, Juana Narcisa y Benedict G.- provenían de un matrimonio bicultural y nacieron y crecieron en un tercer país, o sea en México. Los padres de estos niños fueron Elena Jacobis Shapiro -a veces escrito como Chapiro- nacida en Breslau, Alemania, y su esposo el italiano Benedetto (Benedicto) Barone, quienes llegaron a Mérida en 1903. Benedetto Barone trabajaba en la construcción, y la familia pertenecía a las clases medias (DURÁN-MERK, 2015).

Algunos de estos chicos fueron descendientes de profesionistas o de técnicos, otros de empleados tanto calificados como no-calificados. Los inmigrantes que pertenecían a las capas superiores en su contexto de origen se insertaron en los sectores medios y altos de la sociedad de acogida; sus compatriotas menos favorecidos se incorporaron a las capas inferiores. 
Es difícil generalizar sobre hasta qué punto estos niños fueron vistos de maneras distintas, o sobre cómo fue el entorno en que se educaron. Esto depende de los acuerdos a los que sus padres hayan llegado sobre su educación y de la posición socio-económica de la familia. Lo que la información recabada hasta ahora deja claro es que estas condiciones en el tiempo estudiado no se correlacionan positivamente con una educación internacional: muchos de esos menores asistieron a escuelas públicas de las localidades en que vivieron, se relacionaron con mexicanos de forma continua y cotidiana, y en varios casos tuvieron que trabajar desde relativamente pequeños.

\section{Infancia regional, con referencias a Alemania}

A diferencia del grupo anterior, los pequeños que experimentaron una infancia enraizada en la vida regional, con algunas referencias más bien de tipo práctico y emocional a Alemania, provenían de familias de las clases medias. La clasificación incluye tanto niños de padres nacidos en Alemania, como descendientes de matrimonios germano-mexicanos, tanto en provincia como en la capital mexicana. Este subgrupo se entiende al considerar que desde la generación migrante se dio un proceso de integración sobre todo por razones económicas, lo cual generó una hibridación más rápida. Así, este conjunto tiene más similitudes en términos de patrones de aculturación con la migración de europeos del centro-este en los Estados Unidos que con el imaginario elitista formado en torno de los alemanes en México. ${ }^{4}$

Nuevamente encontramos que esos chicos llevaban nombres en español, sus padrinos fueron personas locales de las clases medias, y contaban con redes familiares extendidas en la sociedad de acogida. Con moderados recursos económicos, estos niños compartieron sus infancias con otros de estratos similares locales: juegos, lecturas, celebraciones, eventos religiosos, vacaciones, etc. Normalmente, vivían en casas rentadas en zonas populares y cambiaban de domicilio con frecuencia. Asistieron a escuelas locales de gobierno, y aunque algunos tuvieron que colaborar con la economía familiar desde chicos, la gran mayoría cursó cuando menos la secundaria. La suma de ellos aprendió

\footnotetext{
${ }^{4}$ Sobre la migración de polacos y húngaros a los Estados Unidos, véase MoRAWSKA (1985).
} 
poco alemán y nunca visitó el país de sus ancestros. Unos cuantos mantuvieron ciertos contactos con parientes en el viejo continente; éstos estaban mayoritariamente limitados a algunas cartas, postales y fotos enviadas a los padres algunas veces al año, incluyendo a veces tarjetas de navidad o algún regalo, como los Adventskalender, calendarios de adviento. Una buena parte de estas interacciones, sin embargo, cesaron alrededor de la Primera Guerra Mundial. No obstante, discursivamente algunos de estos menores se identificaban con Alemania, en especial cuando las actividades económicas de la familia se ubicaban en un nicho ocupacional asociado con ese país, tales como la preparación y venta de alimentos étnicos, o el comercio al menudeo de productos asociados con ese origen.

La enorme mayoría de estos niños, al crecer, contrajo matrimonio con personas oriundas de la localidad donde crecieron. Con cada subsecuente generación los recuerdos de lo "alemán" se romantizaron, al mismo tiempo que se fueron tornando más difusos. Las excepciones fueron encontradas entre familias que contaron con algunos miembros que alcanzaron cierta movilidad social al convertirse en educadores, profesionistas liberales o servidores públicos.

\section{Infancia de integración a las clases trabajadoras}

De las familias alemanas de las clases bajas ningún cónsul germano reporta gran cosa. En el imaginario alemán, para ser considerado como tal era necesario tener una posición económica social desahogada, gozar de prestigio social y de influencias económicas (MENTZ. et. al. ,1988). Sin embargo, un buen número de trabajadores no especializados y también semi-calificados vinieron a probar fortuna a México durante la primera mitad del siglo XX; entre ellos había cerveceros, herreros, mecánicos, nanas y damas de compañía, entre otros oficios. No todos fueron exitosos, y muchos de sus sucesores vivieron infancias mas bien cercanas a las de las clases trabajadoras mexicanas. Además, todavía había en el país un buen número de descendientes de un fallido proyecto de colonización alemana que se llevó a cabo durante el Segundo Imperio Mexicano. Los Ilamados "Villacarlotanos" fueron humildes campesinos y artesanos; sus 
En el ambiente urbano, estos niños asistieron a escuelas de gobierno en zonas populares, como el barrio de Tepito, en la Ciudad de México, o en el área de Zapopan, en Guadalajara. Un buen número apenas terminó la educación primaria, empezando a trabajar como aprendiz en talleres o fábricas desde temprana edad, así como en labores tales como la albañilería, venta de productos en la calle, o como lustradores de zapatos. Mientras que algunas niñas trabajaban en fábricas, ${ }^{5}$ otras desde pequeñas colaboraron con la economía familiar, por ejemplo ayudando a sus madres a lavar y planchar ropa ajena, a preparar comidas para llevar, o a atender algún estaquillo. Para la segunda generación se hablaba mayoritariamente el castellano; a veces se mezclaba ese idioma con el predominante a nivel regional o local -como en el caso de Yucatán, con algo de Maya.

Habría que agregar a este subgrupo los inmigrantes alemanes menores de edad no acompañados, ya que nunca faltó uno que otro que llegara de polizonte a Veracruz en un afán de ganarse la vida de algún modo. Estos menores normalmente se vieron forzados a trabajar desde pequeños para subsistir.

Las niñas descendientes de alemanes humildes que crecieron en zonas rurales mexicanas fueron educadas para llevar una vida de pueblo y contaron con una escolarización muy limitada; los varones fueron criados como campesinos independientes, a veces llamados milperos. Otros pequeños pasaron a formar parte del personal de diversas haciendas agricultoras; los niños laboraban en los campos de henequén, las niñas principalmente en la casa del patrón. ${ }^{6}$ Algunas haciendas henequeneras en Yucatán, por ejemplo, eran verdaderas Torres de Babel, según reporta la historiadora Raquel Padilla Ramos (2011); en ellas había que había maya, mestizos, coreanos, yaqui, canarios, chinos, y personas de otros orígenes culturales: esto explica,

\footnotetext{
${ }^{5}$ Por ejemplo, en Yucatán hay múltiples registros sobre niños y niñas que hacia finales del siglo XIX trabajaban en condiciones que se pueden considerar como explotación tanto en talleres artesanales como en fabricas de ladrillos, de cordón y de cerillos; estas labores se entendieron hasta la tercera década del siglo XX. Véase Remmers, (1981, pp. 833, 837) y Ober, (1887, p. 84).

${ }^{6}$ Las condiciones del trabajo infantil en las haciendas mexicanas ya habían sido reportada por John Kenneth TURNER (1975). Véase también PENICHE RIVERO, (1999).
} 
entonces, el que ciertas prácticas culturales de algunos de esos grupos encuentren lugar también en las memorias de la infancia de los descendientes de alemanes pobres. Selectos rituales y formas de vida de otras culturas con que aquellos extranjeros convivieron fueron adoptados en buena medida, y a veces de forma gradual.

Ya en la segunda generación el idioma principal en que esos chicos se comunicaban fue, en un buen número de casos, una lengua indígena, seguida por algo de español y apenas algunas palabras sueltas en alemán. A partir de los años veinte, con el incremento de la educación rural, empezaría un mayor entrenamiento en el castellano en algunas de las áreas más remotas del país. En relación a las prácticas religiosas, hasta ahora el único caso de este subgrupo que ha sido estudiado en detalle son los descendientes de alemanes en el Yucatán rural: a partir de la segunda generación las tradiciones Maya como el hetzmek (consagración de bebés a los dioses maya) eran celebradas cuando los bebés cumplían los seis meses de edad. También resultaba común que los niños y niñas milperos empezaran a ayudar a sus padres desde 506 años, siendo así tempranamente introducidos a la cosmología Maya. ${ }^{7}$ Algunas de estas tradiciones son cultivadas hasta nuestros días.

Otros tipos de experiencias que merecen atención son las de algunas jovencitas de familias campesinas y artesanas de Alemania que al poco tiempo de llegar a México fueron casadas con hombres de la localidad por sus padres, aparentemente para asegurar la subsistencia de la familia. En esta estrategia se puede ver el aprovechamiento de algunos inmigrantes de las oportunidades estructurales que encontraron para lograr una cierta movilidad ascendente en México, como las ideas sobre "superioridad de la blancura".

El trabajo infantil aparentemente no era visto como un problema por los padres de los niños en este subgrupo, ya que ellos en Alemania habían trabajado también desde relativamente pequeños y su escolaridad había sido bastante corta, lo cual se consideraba Como normal (JACOBEIT y JACOBEIT, 1987, pp. 152, 160-166). Algunos migrantes mostraban gran interés en que al menos uno de sus hijos, normalmente un varón, tuviese acceso a

\footnotetext{
${ }^{7}$ En múltiples regiones de México, buena parte de las tradiciones prehispánicas siguen siendo cultivadas cotidianamente, véase DÁvILA MADRID y TORRES VELÁZQUEZ, 2011.
} 
educación superior, lo cual veían como la única posibilidad de mejorar sus condiciones de vida (SOBRINO CAMPOS, 1994). La forma de vivir la infancia que estos niños experimentaron, pues, fue más bien parecida a la de los niños mexicanos de familias humildes. Como algunos estudiosos han reportado (SOLER DURÁN, 2008, p. 112), durante el Porfiriato la mayoría de los menores locales que habitaban en estados considerados como lejanos, o en comunidades humildes, fueron más bien excluidos y marginados de los procesos de modernización. Esto afectó no sólo el nivel de escolaridad, sino también las condiciones de nutrición, acceso a recursos, y formas de vida.

La identidad de estos pequeños ascendientes de alemanes, pero pertenecientes a los grupos subalternos, era normalmente disputada. Los que mostraban un genotipo centro-europeo, a pesar de ser "blancos" eran normalmente vistos como "güeros de pueblo", o sea de tez blanca y ojos claros pero sin los recursos sociales y culturales que son asociados con las clases superiores. En una sociedad como la mexicana, que aún presta gran atención a los rasgos étnicos, éstos no fueron suficientes a principios del siglo para ser asociado automáticamente con las élites. Mientras tanto, aquellos cuya fisonomía mostraba ya una miscenegación, eran normalmente asignados al grupo local más cercano, o sea, por ejemplo, maya, o cora.

Cabe ahora preguntar: ¿Que papel jugaba Alemania en la construcción de identidad de esos chicos? Aunque en las familias algunas anécdotas sobre el origen alemán continuaron siendo mencionadas por varias generaciones, el bajo nivel de escolaridad no permitía a esas personas comprender lo que eso significaba.

Hubo también un subgrupo de niños que se integró a las experiencias locales como resultado de la circulación de infantes, fenómeno que para la población mexicana en general ya ha sido documentado y que en general tiende a reforzar las diferencias entre las familias de origen y receptoras (BLUM, 2009). En la historia oral de los colectivos aquí estudiados, estos menores de ascendencia alemana habían quedado desamparados por diversas razones - por ser resultado de relaciones fuera del matrimonio, por desintegración familiar, o por pobreza extrema, por ejemplo. El cómo pasaron a formar parte de familias locales era explicado de diversas maneras. En algunos casos se les consideraba como "aceptados", "regalados", o “dados”; esta acepción normalmente se 
En cambio, cuando los pequeños eran más bien seleccionados por familias acomodadas se les refiere como "recogidos" o "adoptados". Es notorio que en este proceso los bebés con piel blanca y ojos claros eran preferidos. Estos infantes que circularon a un status superior tuvieron acceso a los recursos de los grupos acomodados de la localidad; en su mayoría no conocían el origen de sus verdaderos padres y cuando años más tarde eran confrontados con esa realidad algunos se negaban a aceptar un origen humilde.

Al hablar de los chiquillos que quedaron huérfanos habría también que considerar algunos que parecen no haber encontrado una situación estable, y quienes carentes de apoyo pasaron a ser transgresores de la ley desde una temprana edad.

\section{Hijos no reconocidos}

El último subgrupo que he identificado hasta este momento lo forman los hijos de alemanes con mujeres de la localidad que no fueron reconocidos ante el Registro Civil. La tradición oral es muy rica al respecto y algunas historias muestran el desdén que ciertos hombres tuvieron por las mujeres mexicanas e indígenas. ${ }^{8}$ Los niños resultado de estos contactos crecían normalmente dentro de la estructura familiar materna; en casos de precariedad económica eran regalados por la madre. Aunque no es fácil discernir en ocasiones cuales narrativas son verdaderas o no, existen algunos casos en que información documental comprueba la existencia de estos hijos no reconocidos ligándolos directamente a sus padres alemanes. Si el progenitor aceptaba socialmente su rol (aunque no ante el Registro Civil), los pequeños tenían alguna posibilidad de estar en contacto con la cultura alemana, como fue el caso del hijo procreado en Mérida por el

\footnotetext{
${ }^{8}$ La falta de respeto y hasta el desprecio que algunos sentían por las mujeres nativas fue observado por Channing ARNOLD y Frederick J. Tabor Frost (1909, p. 334).
} 
cónsul honorario de Alemania en Yucatán, Otto von Rosenkranz, con una mujer de la localidad (DURÁN-MERK, 2015); esos casos, sin embargo, fueron una minoría.

\section{A modo de cierre}

Centrando el análisis en las experiencias reportadas sobre los encuentros de niños descendientes de migrantes y las sociedades en que crecieron es posible ver cómo las identificaciones étnicas y personales son formadas, o moldeadas, a través del acceso y la utilización de recursos culturales, sociales y materiales. Queda claro que la distinción entre niños protegidos y "trabajadores" no estaba necesariamente marcado por una pertenencia étnica, sino intrínsecamente relacionada con el estatus socio-económico de la familia durante la primera parte del siglo XIX, tanto en Europa como en México.

Otro importante resultado de este análisis es el que la ascendencia extranjera no necesariamente va mano a mano con una infancia trasnacional, sino que depende de varios factores.

Es así que se puede afirmar que los descendientes de alemanes en México tuvieron muy variadas experiencias infantiles. Así mismo, se ha demostrado aquí que más que hablar de un aislamiento casi total de la sociedad receptora hasta la cuarta generación, es posible afirmar que un buen número de descendientes de alemanes en México se valió de diversas estrategias de aculturación. Aparte de la ya previamente documentada auto-segregación de las clases superiores germanas, se encontró una integración paulatina de muchos otros descendientes de alemanes a las prácticas y experiencias de la infancia locales de los subgrupos mexicanos medios y bajos. En ello es posible ver que los niños funcionan dentro de estructuras sociales que facilitan ciertas acciones, en tanto que dificultan otras. Si desde el punto de vista nacionalista alemán "perdían la germanidad" al integrarse a la sociedad de acogida, algunos de esos pequeños se convertían en bilingües, y/o biculturales, retenían selectivamente ciertos marcadores culturales, adquirían destrezas adaptativas de vida y aplicaban estrategias discursivas recurriendo a imaginarios sociales específicos. 
A grosso modo, se pueden distinguir siete variables que afectaron la aculturación de aquellos menores:

- Condiciones estructurales prevalentes en ambas culturas.

- Imaginarios predominantes en Alemania y en la región mexicana donde la familia se asentó.

- Características socio-económicas de la familia.

- Constitución específica familiar, considerando tanto la línea paterna como la materna.

- Marcadores de identidad: edad en que se inmigró, generación a la que se pertenece etnia, género, fisonomía, personalidad, e intereses.

- Previa experiencia migratoria o de transmigraciones.

- Capacidad de agencia personal.

Los resultados de este análisis empírico muestran algo que en realidad no es novedoso, o sea la gran diversificación de las experiencias de la infancia -lo que es original es haberlas identificado en una población que se creía homogénea. La pregunta que surge es: ¿Porqué es que las variaciones de estas experiencias habían sido hasta ahora ignoradas? En mi opinión son cuatro los factores. Primero, mayoritariamente las clases altas han dejado testimonios escritos que han sido preservados en archivos institucionales o bien sido convertidos en libros. No es que los grupos menos favorecidos no hayan legado huellas de su experiencias, sino que éstas deben ser buscadas en archivos familiares, tradiciones orales, y otras fuentes alternativas que sin duda lleva más tiempo y esfuerzo explorar. Segundo, desde el siglo XIX la comunidad alemana en México había insistido en presentarse como un grupo exitoso; esto tuvo como consecuencia que aquellas historias que no coincidían con esta imagen eran silenciadas. Tercero, las personas humildes de origen alemán se encontraron en una posición de disonancia social, en el sentido de que su pertenencia a este grupo étnico era disputada por aquellos con más recursos; esto limitaba la capacidad de ser tomados en cuenta. Y, cuarto, la historia cultural de este grupo en México en buena parte aún se concentra en analizar el impacto económico y político de la migración, dejando de lado los aspectos sociales y familiares. 


\section{Fuentes primarias}

Bundesarchiv Berlin-Lichterfelde

DURÁN-MERK, Alma. Database German-Mexicans, 1865-1950, versión 1.1. Universität Augsburg, 2014.

LAURITZEN, Ekkehard. Briefe aus Mexiko. Heinrich Ude: Aus Lübeck nach Mexiko, transcripciones completas. http://www.lauritzen-hamburg.de/ude_mexico.html, (consultado 20.05.2011).

PIERCE, Agnes. Apuntes para mis hijos y sus nietos (1812-1921). México: INAH, 1996.

SOBRINO CAMPOS, Emma Esther. Recuerdo de la vida de mis padres. Mérida, 1994.

\section{Fuentes secundarias}

AdLeR De LomnITZ, Larissa. Cómo sobreviven los marginados. México: Siglo XXI, 1985.

Adler de LomnitZ, Larissa; Pérez-Lizaur, Marisol. A Mexican Elite Family 1820-1980.

Princeton: Princeton University Press, 1987.

ARnold, Channing; Frost, Frederick J. Tabor. The American Egypt. A Record of Travel in Yucatán. London: Hutchinson Co., 1909.

BerGhe, Gwendoline van der; Berghe, Pierre van der. Compadrazgo and Class in Southeastern Mexico. American Anthropologist. Arlington: American Anthropological Association, vol. 68, no. 5, 1966, pp. 1236-1244.

BERNINGER, George Dieter. La inmigración en México, 1821-1857. México: SEP, Setentas, 1974 .

BERRY, John W. Conceptual Approaches to Acculturation. En: ChUn, Kevin M.; BALLS OrGanista, Pamela; MARín, Gerardo (ed.). Acculturation: Advances in Theory, Measurement, and Applied Research. Washington: APA, 2003, pp. 17-38.

BLUM, Ann S. Domestic Economies. Family, Work, and Welfare in Mexico City, 1884-1943. Lincoln: University of Nebraska, 2009. 
Brettell, Caroline. Situating the Anthropological Perspective. Macro, Meso, and Micro Approaches to the Study of Migration. En: BretTELL, Caroline (ed.) Essays on

Transnationalism, Ethnicity, and Identity. Altamira: Walnut Creek, 2003, pp. 1-7.

Brettell, Caroline; Hollifield, James. Migration Theory. Talking Across Disciplines. New York: Routledge, 2008.

BuchenaU, Jürgen. Tools of Progress: A German Merchant Family in Mexico City, 1865Present. Albuquerque: University of New Mexico Press, 2004.

CAstillo Troncoso, Alberto del. Imágenes y representaciones de la niñez en México a principios del siglo XX. En: GonzAlbo Aizpuru, Pilar; DE LOS ReYES, Aurelio (ed.). Historia de la vida cotidiana en México - Siglo XX. México: COLMEX, 2006, pp. 83-115.

CASTLES, Stephen; Miller, Mark J. The Age of Migration. New York: Guilford Press, 2003.

CORONA BAEZA, Javier Amado. La vida de los descendientes coreanos en Yucatán, Seminario Internacional en Conmemoración del Centenario de la Inmigración Coreana en Yucatán, Seoul, 30.08.2005.

CUnNINGHAM, Hugh. Children and Childhood in Western Society Since 1500. Harlow: Pearson, 2005.

DÁVILA MADRID, Kathia Loyzaga; TORRES VeLÁZqUEZ, Eliud. Infancia y Trabajo en la Cosmovisión Maya. Una Perspectiva tsetsal-tsotsil. Rayuela. Revista Iberoamericana sobre Niñez y Juventud en Lucha por sus Derechos, no. 4 (2011). http://revistarayuela.ednica.org.mx/article/infancia-y-trabajo-en-la-cosmovisi\%C3\%B3nmaya-una-perspectiva-tseltal-tsotsil (consultado 21.10.2012).

Devoto, Fernando. Imágenes de los niños italianos en la inmigración de masas a la Argentina. En: Rodrícuez Jiménez, Pedro; MANARelli, María Emma (ed.). Historia de la infancia en América Latina. Bogotá: Universidad Externado de Colombia, 2007, pp. 459172.

DURÁN-MERK, Alma. 'In Our Sphere of Life'. German-Speaking Immigrants in Yucatán and Their Descendants, 1876-1914. Madrid/Frankfurt am Main: Vervuert, 2015.

DURÁN-MERK, Alma. Villa Carlota. Colonias alemanas en Yucatán. Mérida: CONACULTA, ICY, CEPSA, 2009.

Glick SCHILler, Nina; Basch, Linda; Blanc-Szanton, Christina. Transnationalism: A New Analytic Framework for Understanding Migration. Annals of the New York Academy of Sciences , 1992, pp. 1-24. 
GonzÁlez NAVARRo, Moisés. Los extranjeros en México y los mexicanos en el extranjero. Tres volúmenes. México: COLMEX, 1993 y 1994.

GRANJA CASTRO, Josefina. La infancia como construcción: miradas desde la historia conceptual. En: FENDLER, Ute; FEIERSTEIN, Ruth (ed.). ¿Ser niño? Representaciones de la infancia en África y América Latina. München: AVM Edition, 2013, pp. 55-67.

Hoffmann, Wiebke. Auswandern und Zurückehren. Kaufmannsfamilien zwischen Bremen und Übersee. Münster: Waxmann, 2009.

JACOBEIT, Sigrid; JACOBEIT, Wolfgang. Illustrierte Alltagsgeschichte des deutschen Volkes, 1810-1900. Vol. 2. Leipzig: Urania, 1987.

KRIST, Stefan; WolfSBERGER, Margit. Identität, Heimat. Zugehörigkeit, Remigration”. En: Six-Hohenbalken, Maria (ed.). Anthropologie der Migration. Theoretische Grundlagen und interdisziplinäre Aspekte. Wien: Facultas, 2009, pp. 164-184.

LUCASSEN, Jan; LuCASSEN, Leo. Migration, Migration History, History: Old Paradigms and New Perspectives. In: LUCASSEN, Jan; LUCASSEN, Leo (ed.). Migration, Migration History, History: Old Paradigms and New Perspectives. Bern: Peter Lang, 2005, pp. 9-38.

MAHLER, Sarah J.; PesSAR, Patricia R. Gender Matters: Ethnographers Bring Gender from the Periphery toward the Core of Migration Studies. International Migration Review. New York: Center for Migration Studies, 40, no. 1, 2006, pp. 27-63.

MÉNDEZ REYES, Jesús. Alemanes el noroeste mexicano. Notas sobre su actividad comercial a inicios del siglo XX. Estudios de Historia Moderna y Contemporánea de México. México: UNAM, vol. 66, 2014, pp. 56-86.

MentZ De BoeGE, Brígida von. El Colegio Alemán en México. En: MenTZ, Brígida von; PÉREZ MONFORT, Ricardo; RADKAU, Verena; SPENCER, Daniela. Los empresarios alemanes, el Tercer Reich, la oposición de derecha y Cárdenas, vol. II. México: CIESAS, 1988, pp. 197-250.

MENTZ, Brígida von. Relaciones sociales y vida cotidiana. En: vON MENTZ, Brígida; RADKAU, Verena; SCHARRER, Beatriz; TURNER, Guillermo. Los pioneros del imperialismo alemán en México. México: CIESAS, 1982, pp. 331-362.

MentZ, Brígida von; Pérez Monfort, Ricardo; RAdKAU, Verena; SPEnCER, Daniela. Los empresarios alemanes, el Tercer Reich, la oposición de derecha y Cárdenas, vol. I. México: CIESAS, 1988.

MenTZ, Brígida von; RADKAU, Verena; SCHARRER, Beatriz; TURner, Guillermo. Los pioneros del imperialismo alemán en México. México: CIESAS, 1982. 
MESCHENDÖRFER, Anita. Bürgerliche Kindheit im Deutschland des 18. Jahrhunderts anhand autobiographischer Zeugnisse. Frankfurt am Main: Peter Lang, 1991.

MinTZ, Sidney; WoLf, Eric. An Analysis of Ritual Co-Parenthood (Compadrazgo).

Southwestern Journal of Anthropology. Albuquerque: University of New Mexico, vol. 6, no. 4, 1950, pp. 341-368.

MORAWSKA, Ewa. For Bread with Butter. Life-Worlds of East Central Europeans in Johnston, Pennsylvania, 1890-1940. Cambridge: Cambridge University Press, 1985.

OBER, Frederick A. Travels in Mexico and Life among the Mexicans. Boston: Estes and Lauriat, 1887.

ORTIZ, Fernando. Contrapunteo cubano del tabaco y el azúcar. Barcelona: Ariel, 1973.

ORTOLL, Servando. Vogel: las conquistas y desventuras de un cónsul y hacendado alemán en Colima. Hermosillo: El Colegio de Sonora, 2005.

PAdILla RAmOS, Raquel. Los irredentos parias. Los yaquis, Madero y Pino Suárez en las elecciones de Yucatán, 1911. México: INAH, 2011.

Peniche Rivero, Piedad. La comunidad doméstica de la hacienda henequenera de Yucatán, México, 1870-1915. Mexican Studies/Estudios Mexicanos. Riverside CA y México:

University of California y UNAM, vol. 15, no. 1, 1999, pp. 1-33.

PRECIAdo Zamora, Julia. Por las faldas del Volcán de Colima: cristeros, agraristas y pacíficos. México: Publicaciones de la Casa Chata, 2007.

REMmeRS, Lawrence J. Henequén, the Caste War and Economy of Yucatan, 1846-1883: The Roots of Dependence in a Mexican Region. Tesis doctoral, University of California Los Angeles, 1981.

RojAs MARín, Ana Luisa. Del bosque a los árboles. Puebla: BUAP, 2012.

Romero Castilla, Alfredo. Huellas del paso de los inmigrantes coreanos en tierras de Yucatán y su dispersión por el territorio nacional. En: OTA MISHIMA, María Elena (ed.). Destino México - Un estudio de las migraciones asiáticas a México, siglos XIX y XX. México: COLMEX, 1997, pp. 123-165.

RumbaudT, Rubén G. The Crucible Within: Ethnic Identity, Self-Esteem, and Segmented Assimilation among Children of Immigrants. International Immigration Review. New York: Center for Migration Studies, vol. 28, no. 4, 1997, pp. 748-794. 
Salazar Anaya, Delia; SÁnchez Calleja, María Eugenia. Niños y adolescentes: normas y transgresiones en México, siglos XVII-XX. México: INAH, 2008.

SOLER DURÁN, Alcira. Infancia y exclusión en el México porfirista en los estados de Chiapas y Oaxaca. En: Padilla Arroyo, Antonio; Soler Durán, Alcira; ArRedondo MARTínez, Martha Luz; MARTínez MocteZUMA, Lucía (ed.). La infancia en los siglos XIX y XX. Discursos e imágenes, espacios y prácticas. México: Universidad Autónoma del Estado de Morelos, 2008, pp. 111-133.

SOSENSKI, SUsana. Niños en acción. El trabajo infantil en la Ciudad de México 1920-1932. México: COLMEX, 2010.

SOSENSKI, Susana; JaCKSON AlbARRÁn, Elena. Introducción. En: SOSEnSKI, Susana; JACKSON ALBARRÁN, Elena (ed.). Nuevas miradas a la historia de la infancia en América Latina: entre prácticas y representaciones. México: UNAM, 2012, pp. 7-21.

TURner, John Kenneth. México bárbaro. México: Contenido, 1975.

UNITED NATIONS. International Migration Report. New York: United Nations, 2000. http://www.un.org/esa/population/publications/ittmig2002/2002ITTMIGTEXT22-11.pdf (consultado 27.03.2010).

USEem, Ruth Hill; DownIE, Richard D. Third Culture Kids. Today's Education. Washington: Nacional Education Association, vol. 65, no. 3, 1976, pp. 103-105.

WeLSCH, Wolfgang. On the Acquisition and Possession of Commonalities. En: SCHULzEEnGLER, Frank; HeflfF, Sissy. Transcultural English Studies. Amsterdam: Rodopz, 2009, pp. 3-36. 
Recebido em 28/02/2015 Aprovado em 29/03/2015

Universidade do Estado de Santa Catarina - UDESC Programa de Pós-Graduação em História - PPGH Revista Tempo e Argumento Volume 07 - Número 14 - Ano 2015 tempoeargumento@gmail.com 